\title{
On a Subordination Result of a Subclass of Analytic Functions
}

\section{Risikat Ayodeji Bello}

Department of Mathematics and Statistics, College of Pure and Applied Science, Kwara State University, Malete, Nigeria

Email: reeyait26@gmail.com

How to cite this paper: Bello, R.A (2017) On a Subordination Result of a Subclass of Analytic Functions. Advances in Pure Mathematics, 7, 641-646. https://doi.org/10.4236/apm.2017.711038

Received: March 13, 2017

Accepted: November 21, 2017

Published: November 24, 2017

Copyright $\odot 2017$ by author and Scientific Research Publishing Inc. This work is licensed under the Creative Commons Attribution International License (CC BY 4.0).

http://creativecommons.org/licenses/by/4.0/

\begin{abstract} part of functions belonging to the class $M(1, b)$.

\section{Keywords}

Analytic Function, Univalent Function, Hadamard Product, Subordination
\end{abstract}

In this paper, we investigate a subordination property and the coefficient inequality for the class $M(1, b)$, The lower bound is also provided for the real

\section{Introduction}

Let $A$ denote the class of function $f(z)$ analytic in the open unit disk $U=\{z \in \mathbb{C}:|z|<1\}$ and let $S$ be the subclass of $A$ consisting of functions univalent in $U$ and have the form

$$
f(z)=z+\sum_{k=2}^{\infty} a_{k} z^{k}
$$

The class of convex functions of order $\alpha$ in $U$, denoted as $K(\alpha)$ is given by

$$
K(\alpha)=\left\{f \in S: \operatorname{Re}\left(1+\frac{z f^{\prime \prime}(z)}{f^{\prime}(z)}\right)>\alpha, 0 \leq \alpha<1, z \in U\right\}
$$

Definition 1.1. The Hadamard product or convolution $f * g$ of the function $f(z)$ and $g(z)$, where $f(z)$ is as defined in (1.1) and the function $g(z)$ is given by

$$
g(z)=z+\sum_{k=2}^{\infty} b_{k} z^{k}
$$

is defined as: 


$$
(f * g)(z)=z+\sum_{k=2}^{\infty} a_{k} b_{k} z^{k}=(g * f)(z),
$$

Definition 1.2. Let $f(z)$ and $g(z)$ be analytic in the unit disk $U$. Then $f(z)$ is said to be subordination to $g(z)$ in $U$ and written as.

$$
f(z) \prec g(z), z \in U
$$

if there exist a Schwarz function $\omega(z)$, analytic in $U$ with $\omega(0)=0,|\omega(z)|<1$ such that

$$
f(z)=g(\omega(z)), z \in U
$$

In particular, if the function $g(z)$ is univalent in $U$, then $f(z)$ is said to be subordinate to $g(z)$ if

$$
f(0)=g(0), \quad f(u) \subset g(u)
$$

Definition 1.3. The sequence $\left\{c_{k}\right\}_{k=1}^{\infty}$ of complex numbers is said to be a subordinating factor sequence of the function $f(z)$ if whenever $f(z)$ in the form (1.1) is analytic, univalent and convex in the unit disk $U$, the subordination is given by

$$
\sum_{k=1}^{\infty} a_{k} c_{k} z^{k} \prec f(z), z \in U, a_{1}=1
$$

We have the following theorem:

Theorem 1.1. (Wilf [1]) The sequence $\left\{c_{k}\right\}_{k=1}^{\infty}$ is a subordinating factor sequence if and only if

$$
\operatorname{Re}\left\{1+2 \sum_{k=1}^{\infty} c_{k} z^{k}\right\}>0, z \in U
$$

Definition 1.4. A function $P \in A$ which is normalized by $P(0)=1$ is said to be in $P(1, b)$ if

$$
|P(z)-1|<b, b>0, z \in U
$$

The class $P(1, b)$ was studied by Janwoski [2]. The family $P(1, b)$ contains many interesting classes of functions. For example, for $f(z) \in A$, if

$$
\left(\frac{z f^{\prime}(z)}{f(z)}\right) \in P(1,1-\alpha), 0 \leq \alpha<1
$$

Then $f(z)$ is starlike of order $\alpha$ in $U$ and if

$$
\left(1+\frac{z f^{\prime \prime}(z)}{f^{\prime}(z)}\right) \in P(1,1-\alpha), 0 \leq \alpha<1
$$

Then $f(z)$ is convex of order $\alpha$ in $U$.

Let $F(1, b)$ be the subclass of $P(1,1-\alpha)$ consisting of functions $P(f)$ such that

$$
P(f)=\frac{z f^{\prime}(z)}{f(z)}\left(1+\frac{z f^{\prime \prime}(z)}{f^{\prime}(z)}\right)
$$

we have the following theorem 
Theorem 1.2. [3] Let $P(f)$ be given by Equation (1.6) with $f(z)=z+\sum a_{k} z^{k}$. If

$$
\sum_{k=2}^{\infty}\left(k^{2}+b-1\right)\left|a_{k}\right|<b, b>0
$$

then $P(f) \in F(1, b), \quad 0<b<0.935449$.

It is natural to consider the class

$$
\begin{gathered}
M(1, b)=\left\{f \in A: \sum_{k=2}^{\infty}\left(k^{2}+b-1\right)\left|a_{k}\right|<b, b>0\right\} \\
0<b<0.935449
\end{gathered}
$$

Remark 1.1. [4] If $b=1-\alpha$, then $M(1,1-\alpha)$ consists of starlike functions of order $\alpha, 0 \leq \alpha<1$ since

$$
\sum_{k=2}^{\infty}(k-\alpha)\left|a_{k}\right|<\sum_{k=2}^{\infty}\left(k^{2}-\alpha\right)\left|a_{k}\right|
$$

Our main focus in this work is to provide a subordination results for functions belonging to the class $M(1, b)$

\section{Main Results}

\subsection{Theorem}

Let $f(z) \in M(1, b)$, then

$$
\frac{3+b}{2(3+2 b)}(f * g)(z) \prec g(z)
$$

where $0<b<0.935449$ and $g(z)$ is convex function.

\section{Proof:}

Let

$$
f(z) \in M(1, b)
$$

and suppose that

$$
g(z)=z+\sum b_{k} z^{k} \in C(\alpha)
$$

that is $g(z)$ is a convex function of order $\alpha$.

By definition (1.1) we have

$$
\begin{aligned}
& \frac{3+b}{2(3+2 b)}(f * g)(z) \\
& =\frac{3+b}{2(3+2 b)}\left(z+\sum_{k=2}^{\infty} a_{k} b_{k} z^{k}\right) \\
& =\sum_{k=1}^{\infty} \frac{3+b}{2(3+2 b)} a_{k} b_{k} z^{k}, a_{1}=1, b_{1}=1
\end{aligned}
$$

Hence, by Definition 1.3...to show subordination (2.1) is by establishing that

$$
\left\{\frac{3+b}{2(3+2 b)} a_{k}\right\}_{k=1}^{\infty}
$$


is a subordinating factor sequence with $a_{1}=1$. By Theorem 1.1, it is sufficient to show that

$$
\operatorname{Re}\left\{1+2 \sum_{k=1}^{\infty} \frac{3+b}{2(3+2 b)} a_{k} z^{k}\right\}>0, z \in U
$$

Now,

$$
\begin{aligned}
& \operatorname{Re}\left\{1+2 \sum_{k=1}^{\infty} \frac{3+b}{2(3+2 b)} a_{k} z^{k}\right\} \\
& =\operatorname{Re}\left\{1+\frac{3+b}{3+2 b} z+\sum_{k=2}^{\infty} \frac{3+b}{3+2 b} a_{k} z^{k}\right\} \\
& >\operatorname{Re}\left\{1-\frac{3+b}{3+2 b} r-\frac{3+b}{3+2 b} \sum_{k=2}^{\infty}\left|a_{k}\right| r^{k}\right\} \\
& >\operatorname{Re}\left\{1-\frac{3+b}{3+2 b} r-\frac{1}{3+2 b} \sum_{k=2}^{\infty}\left(k^{2}-b+1\right)\left|a_{k}\right| r^{k}\right\} \\
& >\operatorname{Re}\left\{1-\frac{3+b}{3+2 b} r-\frac{b r}{3+2 b}\right\}=1-r>0
\end{aligned}
$$

Since $(|z|=r<1)$, therefore we obtain

$$
\operatorname{Re}\left\{1+2 \sum_{k=1}^{\infty} \frac{3+b}{2(3+2 b)} a_{k} z^{k}\right\}>0, z \in U
$$

which by Theorem 1.1 shows that $\frac{3+b}{2(3+2 b)} a_{k}$ is a subordinating factor, hence, we have established Equation (2.5).

\subsection{Theorem}

Given $f(z) \in M(1, b)$, then

$$
\operatorname{Ref}(z)>-\frac{3+2 b}{3+b}
$$

The constant factor $\frac{3+2 b}{3+b}$ cannot be replaced by a larger one.

Proof:

Let

$$
g(z)=\frac{z}{1-z}
$$

which is a convex function, Equation (2.1) becomes

$$
\frac{3+b}{2(3+2 b)} f(z) * \frac{z}{1-z} \prec \frac{z}{1-z}
$$

Since

$$
\operatorname{Re}\left(\frac{z}{1-z}\right)>-\frac{1}{2},|z|=r
$$

This implies 


$$
\operatorname{Re}\left\{\frac{3+b}{2(3+2 b)} f(z) * \frac{z}{1-z}\right\}>-\frac{1}{2}
$$

Therefore, we have

$$
\operatorname{Re}(f(z))>-\frac{3+2 b}{3+b}
$$

which is Equation (2.6).

Now to show that sharpness of the constant factor

$$
\frac{3+b}{3+2 b}
$$

We consider the function

$$
f_{1}(z)=\frac{z(3+b)+b z^{2}}{3+b}
$$

Applying Equation (2.1) with $g(z)=\frac{z}{1-z}$ and $f(z)=f_{1}(z)$, we have

$$
\frac{z(3+b)+b z^{2}}{2(3+b)} \prec \frac{z}{1-z}
$$

Using the fact that

$$
|\operatorname{Re}(z)| \leq|z|
$$

We now show that the

$$
\min _{z \in U}\left\{\operatorname{Re}\left(\frac{z(3+b)+b z^{2}}{2(3+b)}\right)\right\}=-\frac{1}{2}
$$

we have

$$
\begin{aligned}
\left|\operatorname{Re}\left(\frac{z(3+b)+b z^{2}}{2(3+b)}\right)\right| & \leq\left|\frac{z(3+b)+b z^{2}}{2(3+b)}\right| \leq|z| \frac{|(3+b)+b z|}{|2(3+b)|} \\
& \leq \frac{|(3+b)+b z|}{2(3+b)} \leq \frac{(3+b)+b}{2(3+2 b)} \leq \frac{3+2 b}{2(3+2 b)}=\frac{1}{2}, \quad(|z|=1)
\end{aligned}
$$

This implies that

$$
\left|\operatorname{Re}\left(\frac{z(3+b)+b z^{2}}{2(3+b)}\right)\right| \leq \frac{1}{2}
$$

and therefore

$$
-\frac{1}{2} \leq \operatorname{Re}\left(\frac{z(3+b)+b z^{2}}{2(3+b)}\right) \leq \frac{1}{2}
$$

Hence, we have that

$$
\min _{z \in U}\left\{\operatorname{Re}\left(\frac{z(3+b)+b z^{2}}{2(3+b)}\right)\right\}=-\frac{1}{2}
$$

That is 


$$
\min _{z \in U}\left\{\operatorname{Re} \frac{3+b}{2(3+2 b)}\left(f_{1} * g(z)\right)\right\}=-\frac{1}{2}
$$

which shows the Equation (2.12).

\subsection{Theorem}

Let

$$
f(z)=z+\sum_{k=2}^{\infty} a_{k} z^{k} \in M(1, b), \quad 0<b<0.935449
$$

then $\left|a_{k}\right| \leq \frac{1}{2}$.

Proof:

Let

$$
f(z)=z+\sum_{k=2}^{\infty} a_{k} z^{k} \in M(1, b)
$$

then by definition of the class $M(I, b)$,

$$
\sum_{k=2}^{\infty}\left(k^{2}+b-1\right)\left|a_{k}\right| \leq b, \quad 0<b<0.935449
$$

we have that

$$
\frac{k^{2}+b-1}{b}-k>0
$$

which gives that

$$
\begin{gathered}
\sum_{k=2}^{\infty} k\left|a_{k}\right| \leq \frac{k^{2}+b-1}{b}\left|a_{k}\right| \leq 1 \\
\text { i.e } \sum_{k=2}^{\infty} k\left|a_{k}\right| \leq 1
\end{gathered}
$$

hence

$$
\begin{gathered}
2 \sum\left|a_{k}\right| \leq 1 \\
\left|a_{k}\right| \leq \frac{1}{2}
\end{gathered}
$$

\section{References}

[1] Wilf, H.S.( 1961) Surbodination Factor Sequence for Some Convex Maps Circle. Proceeding of the American Mathematical Society, 12, 689-693. https://doi.org/10.1090/S0002-9939-1961-0125214-5

[2] Jawonski, W. (1970) Extremal Problems for a Family of Functions with Positive Real Part and for Some Related Families. Annales Polonici Mathematici, 23, 159-177. https://doi.org/10.4064/ap-23-2-159-177

[3] Aghalary, R., Jajangiri, J.M. and Kulkarni, S.R. (2004) Starlikenness and Convexity for Classes of Functions Define d by Subordination. Journal of Inequalities in Pure and Applied Mathematics, 5, No. 2.

[4] Selveraj and Karthikeyan, K.R. (2008) Certain Subordination Results for a Class of Analytic Function Defined by Generalized Integral Operator. International Journal of Computing Science and Mathematics, 2, 166-169. 